\title{
Mapping the territory of renal care: a formative analysis of the cognitive work involved in managing acute kidney injury \\ DOI:
}

10.1080/00140139.2019.1620968

\section{Document Version}

Accepted author manuscript

Link to publication record in Manchester Research Explorer

Citation for published version (APA):

Phipps, D., Blakeman, T., Morris, R., \& Ashcroft, D. (2019). Mapping the territory of renal care: a formative analysis of the cognitive work involved in managing acute kidney injury. Ergonomics, 62(9).

https://doi.org/10.1080/00140139.2019.1620968

\section{Published in:}

Ergonomics

\section{Citing this paper}

Please note that where the full-text provided on Manchester Research Explorer is the Author Accepted Manuscript or Proof version this may differ from the final Published version. If citing, it is advised that you check and use the publisher's definitive version.

\section{General rights}

Copyright and moral rights for the publications made accessible in the Research Explorer are retained by the authors and/or other copyright owners and it is a condition of accessing publications that users recognise and abide by the legal requirements associated with these rights.

\section{Takedown policy}

If you believe that this document breaches copyright please refer to the University of Manchester's Takedown Procedures [http://man.ac.uk/04Y6Bo] or contact uml.scholarlycommunications@manchester.ac.uk providing relevant details, so we can investigate your claim.

\section{OPEN ACCESS}


Mapping the territory of renal care: a formative analysis of the cognitive work involved in managing acute kidney injury

Denham L Phipps $^{1,2 *}$, Thomas M Blakeman ${ }^{1,3}$, Rebecca L Morris ${ }^{1,2}$, Darren M Ashcroft ${ }^{1,2}$

1. School of Health Sciences, The University of Manchester, Manchester, UK

2. NIHR Greater Manchester Patient Safety Translational Research Centre, The University of Manchester, Manchester, UK

3. NIHR Collaboration for Leadership in Applied Health Research and Care Greater

Manchester, The University of Manchester, Manchester, UK

*Address for correspondence: denham.phipps@manchester.ac.uk

\author{
NON-PROOFED POST-PRINT VERSION
}

TO APPEAR IN ERGONOMICS 


\begin{abstract}
The design and evaluation of healthcare work systems requires an understanding of the cognitive work involved in healthcare tasks. Previous studies suggest that a formative approach would be particularly useful to examine healthcare activities for this purpose. In the present study, methods from cognitive work analysis and cognitive task analysis are combined in a formative examination of managing acute kidney injury, an activity that occurs across primary and secondary healthcare settings. The analyses are informed by interviews with healthcare practitioners and a review of practice guidelines. The findings highlight ways in which the task setting influenced practitioners' activity, and ways in which practitioners approached the activity (for example, how they used data to make decisions). The approach taken provided a rich understanding of the cognitive work involved, as well as generating suggestions for the design of work systems to support the clinical task.
\end{abstract}

\title{
Keywords
}

Cognitive work analysis; Cognitive task analysis; Decision making; Healthcare ergonomics; Ergonomics tools and methods

\section{Practitioner summary}

Healthcare tasks often require decision-making in complex and dynamic circumstances, potentially involving collaboration across different practitioner roles and locations. We demonstrate the use of a formative analysis to understand the cognitive work in managing a clinical syndrome across primary and secondary care settings, and consider the implications for work design. 


\section{Introduction}

With a collection of actors and artefacts that can interact in diverse ways, and tasks that vary from the straightforward to the complex, healthcare has long been an area of interest for ergonomics theory and practice (e.g. Waterson, 2009; Buckle et al., 2006; Hignett et al., 2018). The system engineering model of healthcare proposed by Carayon and colleagues (Carayon et al., 2006; Holden et al., 2013) identifies the key role of human factors in the effectiveness of healthcare work systems. This model identifies a range of human factors issues to be investigated in healthcare. One of these issues - which forms the basis of the current paper - is understanding the cognitive activities that occur within a healthcare work setting and should be supported by the work system; for example, the nature of any decision making that occurs in pursuit of work objectives (Patel et al., 2013; Militello et al., 2016).

In addressing the question of understanding cognitive work, Vicente (1999), building upon Rasmussen et al.'s (1994) cognitive systems engineering framework, proposes what he describes as a "formative" approach to the analysis of cognitive work. The basic premise of this approach is that the characteristics of the work setting (including the technical processes, the activities that are performed, and how these activities are allocated and conducted) shape behaviour, and as such are the starting point for analysis and design. In other words, the focus is on the behavioural requirements or constraints that are associated with effective work (Vicente 1999; Hassall \& Sanderson, 2014). Vicente contrasts this analytical focus with that of a so-called "descriptive" approach, which concentrates on describing the behaviour that typically occurs within the setting; here, identification of the setting's behavioural constraints (which in turn define the range of behaviours that are possible in pursuit of work objectives) is incidental to the description of typical behaviour. To adapt an analogy used by Vicente: a descriptive analysis identifies the route taken through a given territory; while a formative 
analysis identifies the features of the territory, such that alternative routes may be taken as these features allow.

In healthcare, parts of Vicente's approach have been used to examine medicines administration in care homes (Lim et al., 2016) and community pharmacies (Phipps, Tam \& Ashcroft, 2017), and to inform work design for activities such as patient monitoring and teletriage (Jiancaro et al., 2014). These studies applied the work domain analysis (WDA) method from Vicente's (1999) cognitive work analysis (CWA) methodology. However, while WDA provides useful insights in its own right, additional methods are available within CWA that have as yet been less often applied to the formative analysis of healthcare tasks. In addition, while Vicente (1999) and Naikar (2010) characterise cognitive task analysis (CTA; e.g. Klein, 1993) as being descriptive rather than formative, others (Militello \& Klein, 2013; Lintern, 2010; Jenkins et al., 2009) have suggested that the data obtained from CTA could also contribute to a formative analysis. As there is a precedent for the use of CTA methods in healthcare (e.g. Baxter et al., 2005; Phipps et al., 2011; Craig et al., 2012; Schnittker et al., 2017), there appears to be value in using CTA alongside CWA as part of a formative analysis in this setting.

The aim of this study was to examine the management across the primary-secondary ${ }^{1}$ healthcare interface of medical situations involving acute kidney injury, using a combination of CWA and CTA. Acute kidney injury (hereafter, AKI) is a clinical syndrome characterised by a rapid deterioration in a patient's renal function. It typically occurs as a complication of other conditions that impair fluid supply to or from the kidney, such as diarrhoea and vomiting (e.g. gastroenteritis) resulting in low circulatory blood volume, and/or as a side

\footnotetext{
1 "Primary care" refers to out-of-hospital settings such as general practices, community treatment centres and community pharmacies. "Secondary care" refers to hospital settings.
} 
effect of medicines usage under particular circumstances. It is an issue of increasing concern internationally; in the United Kingdom, it occurs in an estimated $15 \%$ of unplanned hospital admissions, with a mortality rate of about 30\% (NCGC, 2013; Kerr et al., 2014). The management of patients with AKI depends on community and hospital healthcare practitioners identifying its onset and taking appropriate collaborative action to limit its effects (NCEPOD, 2009; Phipps et al., 2017). A particular challenge is in the post-episode management of patients, given the elevated risk of unplanned hospital readmission or mortality following an AKI episode (Horkan et al., 2015; Silver et al., 2017). The management of patients with actual or suspected AKI, as a distributed and potentially complex activity, therefore lends itself to a formative analysis; hence its adoption for the current study. 


\section{Method}

\subsection{Study design}

Our study used a qualitative design. The framework for data collection and analysis was the first three parts of CWA as described by Vicente (1999), combined with a CTA based on Klein's (1993) recognition-primed decision model (Phillips et al., 2011; Craig et al., 2012). The parts of CWA used in this study - work domain analysis, control task analysis, and strategies analysis - aim to elucidate the nature of the cognitive work demands. The remaining parts focus on the implications of these demands for staffing and resourcing; issues that lie outside the scope of the current paper but are addressed in part in Phipps et al. (2017).

The primary data source was a set of semi-structured interviews conducted by author DLP between July and August 2014, with 7 pharmacists and 6 doctors. These participants were

purposively recruited from three general teaching hospitals in north-west England and a general teaching hospital in the east Midlands; all were recruited on the basis of their having experience in the management of renal conditions. The topic guide for the interview, shown in Appendix 1, was based on the main themes of CWA (Vicente, 1999) and the critical decision method used in CTA (Klein et al., 1989). During each interview, the participant was firstly asked to describe their work in general terms in relation to the management of patients experiencing AKI. The interviewer followed up with more specific questions about the following:

- objectives of the work;

- what needs to be done to meet those objectives;

- how the work is done in practice;

- who or what does the work. 
These questions were intended to elicit information that, while mainly descriptive in nature, broadly corresponded to the CWA's work domain and control task analyses. Therefore, they allowed the researchers to examine formative aspects of the target activity as represented in a CWA.

Each participant was then asked to describe situations in which he or she had encountered AKI, and to give an account of what happened. The interviewer asked follow-up questions to obtain further detail about the key decisions and actions made by the participant, and the information that he or she used in the process. These questions were intended to elicit further details about the task for the CTA and the CWA's strategies analysis.

With the consent of the participant, each interview was audio recorded for subsequent transcription. Approval for the interviews was granted by The University of Manchester's Research Ethics Committee (reference number 13277).

Supplementary data were obtained from transcripts of interviews conducted between June 2014 and January 2015 by author RLM for a separate study (Morris et al., 2016). There, 12 general practice doctors, 10 community pharmacists and 8 primary care nurses from three healthcare regions in north-west and south-west England discussed the work that they undertake to monitor a patient at risk of AKI in the community setting and intervene should AKI occur. During these discussions, participants occasionally described instances of decision making around the identification and treatment of AKI; it is these accounts that were of particular interest for the current study, albeit not directly elicited in the same manner as for the primary data source. 
To assist with our analysis, we also reviewed guidelines on the identification and treatment of AKI (NCGC, 2013; Anathhanam \& Lewington, 2013; NHS England \& UK Renal Registry, 2016). These informed our interpretation of the participants' accounts by further explaining both the work domain in which participants were situated and the decision and actions that characterised the participants' work.

\subsection{Analysis}

For the work domain analysis phase, which describes the system upon which the practitioners are working, we developed an "abstraction-decomposition space" to describe the physiological context of AKI management and an "abstraction hierarchy" to describe the care delivery context. For the abstraction-decomposition space, we used the previous analyses conducted by Hajdukiewicz et al. (2001) and Burns et al. (2009) for cardiac care to populate the highest levels (functional purpose and abstract function). To populate the lower levels (generalised function downwards), we developed a definition for each level based on Naikar et al. (2005), and used the definitions to identify sections of each interview transcript that referred to one of these levels. We used a similar approach to compile the abstraction hierarchy for care delivery; here, we applied a definition for each of all five levels to the transcript. The definitions are shown in Appendix 2.

For the control task analysis phase, we compiled a "contextual activity template" (Naikar et al., 2006), in which discrete situations that occur in relation to AKI are cross-referenced with the generalised functions of care delivery from Table 2, and the control task (that is, what needs to be done with respect to each situation and function) described. In order to generate the detail needed for the template, we identified in each transcript any instances of 
participants identifying and dealing with an AKI episode. From each instance, we noted the circumstances surrounding the episode being discussed (for example when, where and how it became apparent that AKI was occurring, and how the episode progressed), and the decisions and actions taken with respect to that episode. For the strategies analysis phase, which describes how practitioners make decisions and carry out tasks, we reviewed the participants' accounts of dealing with an AKI episode and noted the descriptions provided of ways in which data are gathered and used to resolve the episode. For the purposes of the analysis, gathering and use of data are represented as information flow diagrams (Rasmussen, 1981). The CWA was documented using Version 0.95 of the CWA Tool (Farmilo et al., 2007).

In addition to the CWA representations, we compiled a CTA decision requirements table for each of the three scenarios (initial onset, advanced onset and recovery). In order to compile the table, we revisited the participants' accounts of dealing with an AKI episode and categorised the content of these accounts according to the elements of the RPD model.

The analyses were initially carried out by DLP. They were then reviewed by DMA (a pharmacist with an academic background in medication safety) and TB (a general practitioner with an academic background in kidney health) to ensure that they were technically accurate and represented the accounts provided by the participants. Finally, the technical content of the analysis was reviewed by a renal specialist pharmacist who was not part of the study team. 


\section{Results}

\subsection{The physiological and care delivery context of acute kidney injury}

Figure 1 shows the CWA's abstraction-decomposition space for managing the physiological aspects of AKI. The space is organised across two axes: the level of abstraction (functional purpose; abstract function; generalised function; physical function; physical form) and the level of decomposition (whole body; physiological subsystems; specific organs or medications). The content of the functional purpose and abstract function levels concerns the maintenance of overall well-being, and therefore relates to the "human body" level of decomposition. In the scope of the current analysis, the content of the generalised function level relates only to the renal system, which is a subsystem of the human body. The content of the physical function and physical object levels relates either to basic functions of the renal system in its entirety or to specific components of this system, and therefore spans both levels of decomposition. It is the physical objects that provide clinicians with an indication of the higher functions - that is, renal and whole-body functioning.

\section{INSERT FIGURE 1 HERE}

Figure 2 shows the abstraction hierarchy for care delivery in AKI. Within this representation are two overall purposes to which healthcare professionals and patients work. The first, and most obvious, purpose is promoting patient well-being - ensuring that the patient's physical and psychological wellness is maintained at as high a level as possible. A second purpose is to maintain the viability of the service, by ensuring that clinical activities are carried out in an efficient manner. While some of the abstract functions at the next level down are linked to either one of these purposes or the other (e.g. patient stability contributes to promote patient 
well-being; efficiency contributes to maintain viability as a service), others serve both purposes simultaneously. For example, reducing further interventions or readmission following the resolution of the AKI episode will contribute both to the patient's well-being and to the efficiency of the healthcare system.

\section{INSERT FIGURE 2 HERE}

Returning to Figure 2, the data gathering activities at the physical function level serve different purposes at the generalised function level. To take one of the physical functions as an example, patient monitoring contributes to both prevention of deterioration and management of deterioration. One question that may arise from this set of means-end relationships is whether the data that are generated from the physical functions are used in the same way across the generalised functions, or whether their use differs. In answering this question, the following subsections examine the findings of the additional CWA stages and the CTA.

\subsection{Situation assessment and action across the work functions}

Table 1 shows the contextual activity template for managing an AKI episode. This pertains to three main scenarios that could occur:

- "Initial onset" (when patient deterioration begins to occur but can be halted through self-care or basic medical intervention);

- "Advanced onset" (when patient deterioration progresses to the point where intervention by a renal and/or intensive care specialist is required); and

- "Recovery" (when deterioration has been stopped or reversed, and the focus changes to prevention of a future recurrence). 
A given case may enter all three scenarios, for example if an initial onset of AKI occurs in either primary or secondary care but then leads to further deterioration requiring specialist intervention (i.e., advanced onset) before the episode can be considered resolved (i.e. recovery). Alternatively, the case could begin in the initial onset scenario but then progress straight to recovery without entering advanced onset; for example, if actions taken by a general practitioner or the patient are sufficient to resolve the episode without the need for specialist referral.

\section{INSERT TABLE 1 HERE}

Figure 3 shows two information flow diagrams that were produced from the CWA's strategies analysis. Figure 3(a) pertains to the initial onset and recovery scenarios, which were found to involve the same set of information flows. Here, the primary information sources in include physiological indicators from the physical objects level of the work domain analysis (see Figure 1), plus relevant background information about the patient. The latter include the patient's current signs and symptoms, medicines usage, and current and previous renal functioning (all of which provide the context for interpreting changes in the physiological indicators). Participants' strategies for processing these data were based on symptomatic search, as described by Rasmussen (1981). In the first instance they compared the data with a reference pattern ("patient with suspected AKI requiring action") in order to identify suitable courses of action. If the match between the data and the reference pattern was not clear, the practitioner would make use of decision rules to determine how to proceed. 
For example, it may be difficult to tell at first glance whether or not a high level of serum creatinine in a patient is indicative of deteriorating renal function if the patient appears otherwise well; in such a case, one rule adopted by the participants was either to repeat the measurement and establish whether a further change can be detected over time, or to seek a historical reading to act as a baseline against which the current reading can be compared. Some participants referred to current or previous measures of glomerular filtration rate (GFR), a measure of kidney filtration, as a data source. In fact, GFR as currently assessed is not very well suited to assessing AKI directly, due amongst other things to the time lag between a change in kidney function and a corresponding change in the measured GFR (Molitoris, 2012). However, it appeared that participants were using the trend in GFR to develop a general picture of renal function, and to inform decisions about adjusting drug doses.

Figure 3(b), meanwhile, pertains to the advanced onset scenario. As in the other scenarios, courses of action in the advanced onset scenario (whose data sources listed in Table 1) are arrived at mainly through symptomatic search. Here, though, participants also referred to using the hypothesis-and-test mode of symptomatic search (for example, considering whether an associated or underlying condition such as acute tubular necrosis has occurred), or reverting to topographic search (systematically examining the patient's renal system), to resolve any ambiguities in pattern matching.

\section{INSERT FIGURE 3 HERE}

Tables 2(a), 2(b) and 2(c) show the decision making elements in CTA for the initial onset, advanced onset recovery scenarios respectively. The expectancies in these tables include the 
potential for further understanding about the clinical situation to be obtained through additional investigation, with the advanced onset scenario (Table 2(b)) showing a more detailed clinical investigation than is carried out in the other scenarios. They also include effects that may result from a given action, which effectively resolve the situation; for example, adjusting medication leading to kidney function stabilising. As the rightmost column in each table shows, relationships between action and effect are derived from both patient physiology and care delivery (depicted in Figures 1 and 2 respectively). As an example of how this is manifested in practice: the presence of multiple health conditions creates the need for any medication regimen to provide optimal treatment for all conditions, unless one is prioritised over the others. However, healthcare professionals and patients will also be trading off the different priorities regarding care delivery, such as efficiency (how should limited and costly healthcare resources be used to best effect?). Hence, a link between the CTA and the work domain analysis phase of the CWA is that the latter describes the system that gives rise to the data captured in the former; this which allows our use of the work domain analysis to populate part of the CTA tables.

\subsection{AKI management across the care settings}

In general terms, the scenarios and functions in Table 1 may be mapped onto clinical settings. The initial onset and recovery scenarios are usually shared between primary and secondary care settings, while advanced onset is largely managed in secondary care. Similarly, the prevention, detection and recovery functions are usually shared, while the management of deterioration function typically occurs in a hospital. 
Comparing the different scenarios and functions in our analysis suggest that there are both commonalities and differences between them, which might translate to the respective clinical settings. As suggested earlier, there appears from the information flow diagrams to be an "essential set" of data elements and decisions across the scenarios. For example:

- in order to determine whether renal function is improving, deteriorating or stable, examine the change in basic physiological indicators (such as blood pressure and creatinine level);

- in order to effect a change in renal functioning, consider changing the patient's medication.

At a more strategic level, though, the contextual activity template indicates shows slightly different considerations for each phase. During initial onset, the main considerations are screening out patients at risk of developing AKI given the basic indicators, and attempting to forestall deterioration of at-risk patients by adjusting medication and keeping the patient well hydrated. During advanced onset, the main concern is with investigating the cause of deterioration using a more comprehensive set of physiological markers (for example, fluid balance measures and biopsy results) and carrying out further procedures in addition to medication changes until deterioration is reversed or at least stopped. During recovery, the concern changes to comparing successive measures of the basic indicators and implementing follow-up activities (such as long-term changes to medication) to ensure that renal function continues to improve or stabilise.

In addition, comparing recovery with the other scenarios (Table 2) shows that the components of decision making for initial and advanced onset are more explicitly defined than are those for recovery, despite the similarities in information flow identified in Figure 2. 
Participants reported decision-making in the recovery phase as relying more on case-by-case judgement. In order to make a judgement, they considered how the basic indicators were changing or were expected to change, especially as a result of adjusting medication. Participants' appraisal of changes to the indicators was informed by the patient's overall health needs (for example, managing co-morbidities) and the need to use health service resources in a cost-effective manner (for example, by adhering as closely as possible to the organisation's preferred list of medicines). 


\section{Discussion}

\subsection{Understanding the cognitive work involved in AKI}

We have demonstrated the use of a formative approach, integrating methods from CWA and CTA, to examine the management of care scenarios involving potential or actual AKI. This leads to two general insights about the cognitive work involved in this task. Firstly, it requires the practitioner to manage two "systems": the renal system, in its own right and in interaction with other physiological systems; and care delivery system, which has several purposes and priorities to be traded-off in practice. Both provide various functions and physical objects by which healthcare professionals and patients can control the two systems for example, medicines supply and medicines taking.

Secondly, management of the clinical situation can be characterised in terms of interplay between situation assessment and taking action; in effect, a "decision cycle" that is mediated by the work domain (Lipshitz, 1993). Practitioners may use different strategies to move between assessment and action; for the most part, these involved comparing the actual data with a reference pattern, but could also involve the application of decision rules or a more deliberate examination of the system (i.e. the patient) if there is any ambiguity in understanding the situation.

Thirdly, these strategies vary according to the patient's state. Specifically, explicit rules of thumb appear to be more prevalent in the detection of and response to AKI, with the rules differing according to the data available to the practitioner and the task requirements (determining whether there is a problem and whether it can be easily resolved, versus investigating and addressing a more advanced onset of the problem). However, post-episode 
treatment appears to be less amenable to rules of thumb; instead, decisions are made with direct reference to the physiological and care delivery context.

Our findings also illustrated conceptual links between CWA and CTA. The notion of a decision cycle has been discussed with regard to CTA, but Rasmussen's (1981) description of symptomatic search (which informs strategies analysis phase of CWA) refers to "correcting the system". This is when an actor, rather than hypothesising symptoms and trying to determine whether these are present in a given system, instead hypothesises effects that may occur as the result of taking actions on the system, and then executes those actions to see what happens. The latter, which Rasmussen suggests incurs less mental load, is similar to "hedge clipping" in Lipshitz's (1993) model, as well as to the "closed-loop" style of decisionmaking characterised by Flach et al. (2017). Meanwhile, Klein \& Militello (2001) note that the behavioural constraints examined in CWA, although not the main focus of a CTA, are an important contextual issue that would inform task analysis.

In our findings, the work domain analysis was identified as representing the systems within which decisions take place, and which both elicits and determines the effect of any actions carried out, and hence - in line with the argument made by Militello et al. - its output forms the context for decision making in the decision requirements tables. This includes both patient physiology (consistent with Hajdukiewicz et al., 2001), and the care system (consistent with Effken et al., 2011). Previous studies have found the application of a physiological work domain analysis to be limited by the complexity of biological systems; although it is possible that similar problems occur when analysing organic, as opposed to engineered, organisational systems (Jiancaro et al., 2014; Dekker et al., 2013). Indeed, while both perspectives appear relevant to the subject matter of the current study, there remain 
outstanding questions from our analysis. One concerns the issues related to inter-professional and inter-organisational working, which are implicit in, but not fully exposed by, the analysis (Phipps et al., 2017). It is possible that adding the social organisation and cooperation analysis phase of the CWA may have made such issues more salient. A second question concerns the physiological and care delivery effects that are to be achieved during recovery from an AKI episode. It is not immediately obvious how these are prioritised for a given individual; this is possibly a matter of experiential or individual difference factors, such as a patient's desire for a sense of control over his or her health (Morris et al., 2011).

\subsection{Implications for work design arising from the analysis}

Recent policy recommendations concerning the management of AKI (NHS England \& UK Renal Registry, 2014; NHS England, 2015) allude to the need for work structures that support this activity (Bailey et al., 2018). Hence, it would be useful to consider how the findings from the current study might inform the development or evaluation of suitable structures structures. While we do not offer a detailed set of design or evaluation criteria here, some hypotheses might be drawn from our analysis following previous studies on the application of CWA or CTA (Klein et al., 1997; Naikar \& Sanderson, 2001; Naikar, 2006; Hajdukiewicz et al., 2001; Miller et al., 2017; Read et al., 2015).

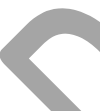

Firstly, the CWA's abstraction-decomposition space identifies different levels of aggregation for understanding the patient with AKI. The elements at the bottom of the hierarchy are those which practitioners monitor (e.g. filtration rate) or use (e.g. medication) in the first instance. These, though, are used to control the processes further up in the hierarchy (blood and water flow, and nutrient and waste exchange; both a product of the processes at the next 
level down). Therefore, it may be important to make the lower-level elements, and their link to higher-level processes, salient to actors within the system.

Secondly, the CWA's information flow diagrams indicate which data need to be provided to practitioners, and how they might use the data (i.e. looking for particular patterns that confirm the patient state). The CTA's decision requirements tables indicate possible interpretations of the data, in addition to further changes or data sources that are relevant to understanding the patient's condition (for example, changes in filtration rate and urinary output following an improvement in renal functioning). They also describe courses of action that could be followed at a particular point; either to gain a better understanding of the patient's condition or to rectify any problems that have been identified with the patient. It may be important, therefore, to incorporate the information flows and decision requirements generated here into the design of any decision support provided to actors.

Thirdly, given the potential for some of the task work to span different parts of the healthcare system, the contextual activity template might be useful for ensuring that tasks are allocated in a systematic manner (for example, duplication or omission of task work is minimised, and workload is spread as much as possible). If the activities in the template are mapped onto an organisational structure, this could suggest which activities are in particular need of measures to support task coordination due to their crossing departmental or organisational boundaries.

Extending these hypotheses further, the analysis findings may inform any attempt to reconfigure renal care services - or even inspire a reconfiguration. For example, future studies could investigate the feasibility of presenting the data and decision points identified here to other actors with a potential role in managing AKI - such as community-based 
healthcare professionals and patients themselves - in order to facilitate the reallocation of taskwork beyond the current settings (the general practice and the renal unit). Another, related, avenue of exploration could be the routine use of these data outside of a specialist setting to predict and forestall an AKI episode, or facilitate earlier intervention in the case of an episode that would lead to deterioration. These are more speculative suggestions, but are in keeping with Vicente's philosophy that a formative analysis lays the foundation for considering what could be done, as well as improving what is done. Incidentally, this latter mode of applying formative analysis to healthcare aligns with the observation by Amalberti et al. (in press), amongst others, that current economic, demographic and technological changes will bring about the need for future reconfiguration and redesign of healthcare services - for example, shifting the focus from episodic care in a single setting to long-term care across multiple settings.

\subsection{Reflections on the study methods}

The data collection method used in this study warrants further comment. Our data were obtained from semi-structured interyiews that allowed for some general discussion around the topic of managing acute kidney injury. This might be contrasted with a more structured interview design, such as that suggested for the critical decision method (e.g. Klein et al., 1989). The latter allows the investigator to obtain data that are consistent with a chosen conceptual model in an efficient manner. Crucially, it also helps to ensure that key issues relating to the model are properly elicited during data collection. For example, in the current study, the CTA component of the analysis assumes that the expectancies relating to each given scenario were sufficiently explored. However, a less structured approach allows the investigator to inquire about topics beyond the scope of a particular conceptual model selected for the analysis; for example, in this study, the interprofessional and inter- 
organisational relationships that have a bearing on how work is carried out. This makes the data more amenable to being examined from different conceptual standpoints, which was the case in the current study. It does, though, require the investigator to be mindful of the models that might be subsequently applied to the data, and to ensure that these are covered as much as possible during the data elicitation. Alternatively, if particular points are not adequately covered, this might be addressed by the use of other data sources such as documentary analysis, subject matter expert review, or observations. Indeed, Schnittker et al. (2019) demonstrates the value of data triangulation for understanding cognitive work in healthcare and translating this understanding to work design recommendations.

As was the case in the current study, the decision about how to collect data for a formative analysis is likely to be in part a pragmatic one, dictated by the time available with practitioners and how much information is already available about the work. Relevant details about the work context could be drawn from data already obtained from a previous study; although, given that such studies may be oriented towards contemporaneous or retrospective evaluation rather than prospective examination of possible work systems, some follow up data collection against the CWA and CTA models could be required for the purpose of a formative analysis. In the current study, documentary and subject matter expert review were available to address any knowledge gaps from the interviews. In fact, these may well have been vital to allow a full consideration of the formative aspects of the task, as it is unclear to what extent the abstraction hierarchies and contextual activity templates in particular could be populated on the basis of the interviews alone. It is possible that further understanding might also have been gained from observational data, but resource constraints did not allow us to collect these for the current study. 


\section{Conclusion}

The management of situations where AKI may be present involves cognitive work across both primary and secondary healthcare. As such, it is an example of an activity that could be examined using a formative approach. In this study, we have used both cognitive work analysis and cognitive task analysis to examine the work involved and identify requirements for the design of work systems to improve the management of AKI. Our findings demonstrate the understanding that can be gained about healthcare activities by combining the two approaches in a formative framework.

\section{Acknowledgements}

We would like to acknowledge the National Institute for Health Research (NIHR) Clinical Research Network for its assistance with data collection, and to thank the practitioners and service users who took part in our study. We would also like to thank Kathrine Parker (Manchester University NHS Foundation Trust) for providing subject matter expertise, and two anonymous reviewers for their efforts in developing a previous version of our manuscript.

\section{Funding}

This study was funded by the National Institute for Health Research (NIHR) Greater Manchester Patient Safety Translational Research Centre and the NIHR School for Primary Care Research. The views expressed in this article are those of the author and not necessarily those of the NHS, NIHR or the Department of Health and Social Care.

\section{References}


Amalberti, R., Vincent, C., Nicklin, W., \& Braithwaite, J. (in press). Coping with more people with more illness, Part 1: the nature of the challenge and the implications for safety and quality. International Journal for Quality in Healthcare, doi: 10.1093/intqhe/mzy235 Anathhanam, S., \& Lewington, A.J.P. (2013). Acute kidney injury. Journal of the Royal College of Physicians of Edinburgh, 43, 323-329.

Bailey, S., Blakeman, T., Brisley, A., Howard, S., \& Weisshar, C. (2018). Improvement in context: an ethnographic study of quality improvement programmes for acute kidney injury. Manchester: NIHR CLAHRC Greater Manchester.

Baxter, G.D., Monk, A.F., Tan, K., Dear, P.R., \& Newell, S.J. (2005). Using cognitive task analysis to facilitate the integration of decision support systems into the neonatal intensive care unit. Artificial Intelligence in Medicine, 35(3), 243-257.

Buckle, P., Clarkson, P.J., Coleman, R., Ward, J., \& Anderson, J. (2006). Patient safety, systems design and ergonomics. Applied Ergonomics, 37, 491-500.

Burns, C.M., Enomoto, Y., \& Momtahan, K. (2009). A cognitive work analysis of cardiac care nurses performing teletriage. In A.M. Bisantz \& C.M. Burns (Eds.), Applications of Cognitive Work Analysis (pp. 149-173). Boca Raton, FL: CRC Press.

Carayon, P., Hundt, A.S., Karst, B.-T., Gurses, A.P., Alvarado, C.J., Smith, M., \& Brennan, P.F. (20060. Work system design for patient safety: the SEPIS model. Quality and Safety in Health Care, 15(Suppl. I), i50-i58.

Craig, C., Klein, M.I., Griswold, J., Gaitonde, K., McGill, T., \& Halldorsson, A. (2012). Using cognitive task analysis to identify critical decisions in the laparoscopic environment. Human Factors, 54, 1025-1039.

Dekker, S., Bergström, J., Amer-Wåhlin, I., \& Cilliers, P. (2013). Complicated, complex and compliant: best practice in obstetrics. Cognition, Technology \& Work, 15, 189-195. 
Effken, J.A., Brewer, B.B., Logue, M.D., Gephart, S., \& Verran, J.A. (2011). Using cognitive work analysis to fit decision support tools to nurse managers' work flow. International Journal of Medical Informatics, 80, 698-707.

Farmilo, A., Hone, G., \& Whitworth, I. (2007). The CWA Tool, version 0.95. Shrivenham: Cranfield University.

Fitzpatrick, G., \& Ellingsen, G. (2013). A review of 25 years of CSCW research in healthcare contributions, challenges and future agendas. Computer Supported Collaborative Work, 22, 609-655.

Flach, J.M., Feufel, M.A., Reynolds, P.L., Parker, S.H., \& Kellogg, K.M. (2017).

Decisionmaking in practice: the dynamics of muddling through. Applied Ergonomics, 63, $133-141$.

Hassall, M.E., \& Sanderson, P.M. (2014). A formative approach to the strategies analysis phase of cognitive work analysis. Theoretical Issues in Ergonomics Science, 15, 215-261.

Hajdukiewicz, J.R., Vicente, K.J., Doyle, D.J., Milgram, P., \& Burns, C.M. (2001). Modeling a medical environment: an ontology for integrated medical informatics design.

International Journal of Medical Informatics, 62, 79-99.

Hignett, S., Lang, A., Pickup, L., Ives, C., Fray, M., McKeown, C., Tapley, S., Woodward, M., \& Bowie, P. (2018). More holes than cheese: what prevents the delivery of effective, high quality and safe healthcare in England? Ergonomics, 61,

Holden, R.J., Carayon, P., Gurses, A.P., Hoonakker, P., Hundt, A.S., Ozok, A.A., \& RiveraRodriguez, J. (2013). SEIPS 2.0: a human factors framework for studying and improving the work of healthcare professionals and patients. Ergonomics, 11, 1669-1686.

Horkan, C., Purtle, S., Mendu, M., Moromizato, T., Gibbons, F., \& Christopher, K. (2015). The association of acute kidney injury in the critically ill and postdischarge outcomes: a cohort study. Critical Care Medicine, 43, 354-364. 
Jenkins, D.P., Stanton, N.A., Salmon, P.M., Walker, G.H., \& Rafferty, L. (2009). Using the decision ladder to add a formative element to naturalistic decision making research. Paper presented at the $9^{\text {th }}$ International Conference on Naturalistic Decision Making, London, June 2009.

Jiancaro, T., Jamieson, G.A., \& Mihailidis, A. (2014). Twenty years of cognitive work analysis in health care: a scoping review. Human Factors, 8, 3-22.

Johnson, J.K., Farnan, J.M., Barach, P., Hesselink, G., Wollersheim, H., Pijnenborg, L Kalkman, C., Arora, V.M. (2012). Searching for the missing pieces between the hospital and primary care: mapping the patient process during care transitions. BMJ Quality and Safety, 21, i97-i105.

Kerr, M., Bedford, M., Matthews, B., \& O’Donoghue, D. (2014). The economic impact of acute kidney injury in England. Nephrology Dialysis Transplantation, 29, 1362-1368.

Klein, G.A. (1993). A recognition-primed decision model of rapid decision making. In G.A. Klein, J. Orasanu, R. Calderwood \& C.E. Zsambok (Eds.), Decision Making in Action: Models and methods (pp. 138-147). Norwood, NJ: Ablex.

Klein, G., Kaempf, G.L., Wolf, S., Thorsden, M., \& Miller, T. (1997). Applying decision requirements to user-centred design. International Journal of Human-Computer Studies, $46,1-15$.

Klein, G.A., Calderwood, R., \& MacGregor, D. (1989). Critical decision method for eliciting knowledge. IEEE Transactions on Systems, Man and Cybernetics, 19, 462-472.

Klein, G., \& Militello, L. (2001). Some guidelines for conducting a cognitive task analysis. In E. Salas (Ed.), Advances In Human Performance And Cognitive Engineering Research Volume 1 (pp. 163-199). Bradford: Emerald Group Publishing.

Klein, G., Pliske, R., Crandall, B., \& Woods, D.D. (2005). Problem detection. Cognition, Technology and Work, 7, 14-28. 
Lim, R.H.M., Anderson, J.E., \& Buckle, P.W. (2016). Work domain analysis for understanding medication safety in care homes in England: an exploratory study. Ergonomics, 59, 15-26.

Lintern, G. (2010). A comparison of the decision ladder and the recognition-primed decision model. Journal of Cognitive Engineering and Decision Making, 4, 304-327.

Lipshitz, R. (1993). Converging themes in the study of decision making in realistic settings. In G.A. Klein, J. Orasanu, R. Calderwood, \& C.E. Zsambok (Eds.), Decision Making in Action: Models and methods (pp. 103-137). Westport, CT: Ablex.

Militello, L.G., \& Klein, G. (2013). Decision-centred design. In J.D. Lee \& A. Kirlik (Eds.), The Oxford Handbook of Cognitive Engineering (pp. 261-271). Oxford: Oxford University Press.

Militello, L.G., Saleem, J.J., Borders, M.R., Sushereba, C.E., Haverkamp, D., Wolf, S.P., \& Doebbeling, B.N. (2016). Designing colorectal cancer screening decision support: a cognitive engineering enterprise. Journal of Cognitive Engineering and Decision Making, 10, 74-90.

Miller, M.J., McGuire, K.M., \& Feigh, K.M. (2017). Decision support system requirements definition for human extravehicular activity based on cognitive work analysis. Journal of Cognitive Engineering and Decision Making, 11, 136-165.

Molitoris, B.A. (2012). Measuring glomerular filtration rate in acute kidney injury: yes, but not yet. Critical Care, 16, 158.

Morris, R.L., Ashcroft, D., Phipps, D., Bower, P., O’Donoghue, D., Roderick, P., Harding, S., Lewington, A., \& Blakeman, T. (2016). Preventing Acute Kidney Injury: a qualitative study exploring "sick day rules" implementation in primary care. BMC Family Practice, 17, 91. 
Morris, R.L., Sanders, C., Kennedy, A. P., \& Rogers, A. (2011). Shifting priorities in multimorbidity: a longitudinal qualitative study of patient's prioritization of multiple conditions. Chronic Illness, 7, 142-161.

Naikar, N. (2006). Beyond interface design: further applications of cognitive work analysis. International Journal of Industrial Ergonomics, 36, 423-428.

Naikar, N. (2010). A comparison of the decision ladder template and the recognition-primed decision model. Report DSTO-TR-2397. Victoria: Defence Science and Technology Organisation.

Naikar, N., Hopcroft, R., \& Moylan, A. (2005). Work domain analysis: theoretical concepts and methodology. Report DSTO-TR-1665. Victoria: Defence Science and technology Organisation.

Naikar, N., Moylan, A., \& Pearce, B. (2006). Analysing activity in complex systems with cognitive work analysis: concepts, guidelines and case study for control task analysis. Theoretical Issues in Ergonomics Science, 7, 371-394.

Naikar, N., \& Sanderson, P.M. (2001). Evaluating design proposals for complex systems with work domain analysis. Human Factors, 43, 529-542.

NCEPOD (2009). Adding Insult to Injury: a review of the care of patients who died in hospital with a primary diagnosis of acute kidney injury. London: National Confidential Enquiry into Patient Outcome and Death.

NCGC (2013). Acute Kidney Injury: prevention, detection and management up to the point of renal replacement therapy. London: National Clinical Guideline Centre.

NHS England, \& UK Renal Registry (2014). Acute kidney injury warning algorithm best guidance. Bristol: UK Renal Registry.

NHS England, \& UK Renal Registry (2016). Guidelines for medicines optimisation in patients with acute kidney injury. Bristol: UK Renal Registry. 
NHS England (2015). Commissioning for quality and innovation: guidance for 2015/16.

Downloaded from https://www.england.nhs.uk/wp-content/uploads/2015/03/9-cquin-guid2015-16.pdf, $10^{\text {th }}$ July 2018.

Patel, V.L., Kaufman, D.R., \& Kannampallil, T.G. (2013). Diagnostic reasoning and decision making in the context of health information technology. Reviews of Human Factors and Ergonomics, 8, 149-190.

Phillips, J., McCloskey, M.J., McDermott, P.L., Wiggins, S.L., Battaglia, D.A., Thordsen, M.L., \& Klein, G. (2001). Decision-centred MOUT training for small unit leaders. Report to the US Army Research Institute for the Behavioural and Social Sciences. Fairborn, OH: Klein Associates.

Phipps, D.L., Meakin, G.H., \& Beatty, P.C.W. (2011). Extending hierarchical task analysis to identify cognitive demands and information design requirements. Applied Ergonomics, 42, $741-748$

Phipps, D.L., Morris, R.L., Blakeman, T., \& Ashcroft, D.M. (2017). What is involved in medicines management across care boundaries? A qualitative study of healthcare practitioners' experiences in the case of acute kidney injury. BMJ Open, 7, e001765. doi: 10.1136/bmjopen-2016-011765

Phipps, D.L., Tam, W.V., \& Ashcroft, D.M. (2017). Integrating data from the UK National Reporting and Learning System with work domain analysis to understand patient safety incidents in community pharmacy. Journal of Patient Safety, 13, 6-13.

Rasmussen, J. (1981). Models of mental strategies in process plant diagnosis. In J. Rasmussen \& W.B. Rouse (Eds.), Human Detection and Diagnosis of System Failures (pp. 241-258). New York: Plenum.

Rasmussen, J., Pejterson, A.M., \& Goodstein, L.P. (1994). Cognitive Systems Engineering. Chichester: Wiley. 
Read, G.J.M., Salmon, P.M., Lenné, M.G., \& Stanton, N.A. (2015). Designing sociotechnical systems with cognitive work analysis: putting theory back into practice. Ergonomics, 58, $822-851$.

Schmidt, T., \& Wiil, U.K. (2015). Identifying patients at risk of deterioration in the joint emergency department. Cognition, Technology \& Work, 17, 529-545.

Schnittker, R., Marshall, S., Horberry, T., Young, K., \& Lintern, G. (2017). Exploring decision pathways in challenging airway management episodes. Journal of Cognitive Engineering and Decision Making, 11, 353-370.

Schnittker, R., Marshall, S.D., Horberry, T., \& Young, K. (2019). Decision-centred design in healthcare: the process of identifying a decision support tool for airway management. Applied Ergonomics, 77, 70-82.

Siegel, A.W., \& Schraagen, J.M.C. (2017). Beyond procedures: team reflection in a rail control centre to enhance resilience. Safety Science, 91, 181-191.

Silver, S.A., Harel, Z., McArthur, E., Nash, D.M., Acedillo, R., Kitchlu, A., Garg, A.X., Chertow, G.M., Bell, C.M., \& Wald, R. (2017). 30-day readmissions after an acute kidney injury hospitalization. The American Journal of Medicine, 130, 163-172.

Vicente, K.J. (1999). Cognitive Work Analysis: Toward safe, productive, and healthy computer-based work. Mahwah, NJ: Lawrence Erlbaum.

Waterson, P. (2009). A critical review of the systems approach within patient safety research. Ergonomics, 52, 1185-1195. 
TABLES AND FIGURES

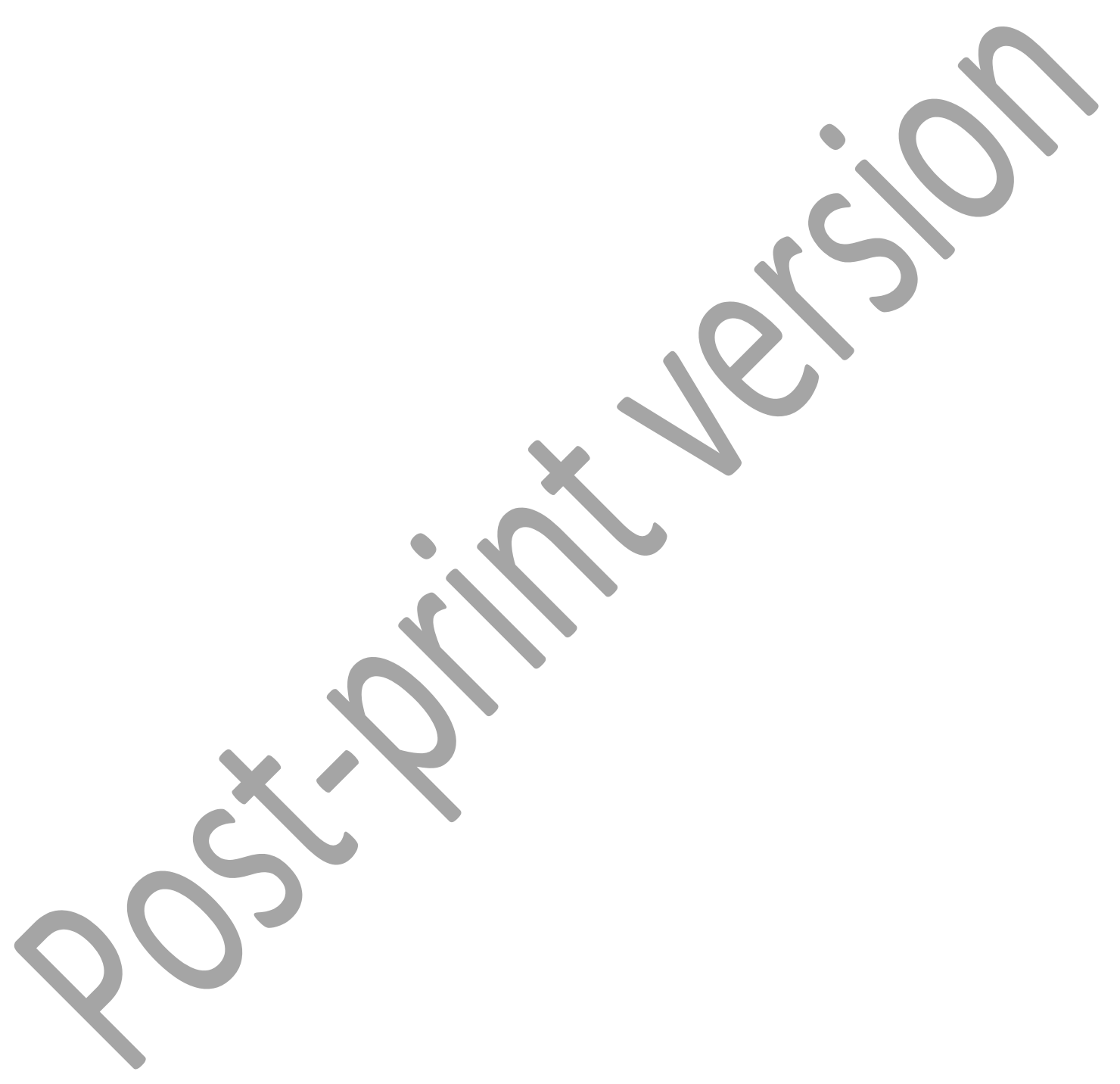


Table 1. Contextual activity template summarising the control tasks for managing AKI

\begin{tabular}{|c|c|c|c|}
\hline \multirow[b]{2}{*}{ Function } & \multicolumn{3}{|c|}{ Scenario } \\
\hline & Initial onset (start of deterioration & Advanced onset (deterioration has progressed) & Recovery (deterioration has been resolved) \\
\hline $\begin{array}{l}\text { Prevention of } \\
\text { deterioration }\end{array}$ & $\begin{aligned} & \text { Data: } \\
&- \text { Patient signs and symptoms } \\
& \text { (e.g. tiredness; diarrhoea; } \\
& \text { urinary infection) } \\
&- \text { Medical history } \\
&- \text { Medicines usage } \\
& \text { State: } \\
& \text { Problematic condition requiring } \\
& \text { action? } \\
& \\
& \text { Actions: } \\
& \text { - } \text { Adjust medication } \\
& \text { - } \text { Maintain or increase } \\
& \text { hydration } \\
&- \text { Collect data to detect } \\
& \text { deterioration }\end{aligned}$ & Not applicable, as deterioration has already occurre & $\begin{array}{l}\text { Patient signs and symptoms (e.g. tiredness; } \\
\text { diarrhoea; urinary infection) } \\
\text { - Current and previous renal functioning: } \\
\circ \quad \text { Urinary output (volume and content - in } \\
\text { particular, presence of protein) } \\
\circ \quad \text { Urea and electrolytes (in particular } \\
\text { serum creatinine, phosphate, } \\
\text { bicarbonate, potassium) } \\
\quad \text { Glomerular filtration rate (especially if } \\
\text { dosing anticoagulant or antiviral } \\
\text { medication) } \\
\text { - Blood pressure } \\
\text { - Medical history } \\
\text { - Medicines usage } \\
\text { State: } \\
\text { Patient stable? } \\
\text { Actions: } \\
\text { - Establish or revise care plan }\end{array}$ \\
\hline
\end{tabular}




\begin{tabular}{|c|c|c|c|}
\hline \multirow[b]{2}{*}{ Function } & \multicolumn{3}{|c|}{ Scenario } \\
\hline & Initial onset (start of deterioration) & Advanced onset (deterioration has progressed) & Recovery (deterioration has been resolved) \\
\hline $\begin{array}{l}\text { Detection of } \\
\text { deterioration }\end{array}$ & 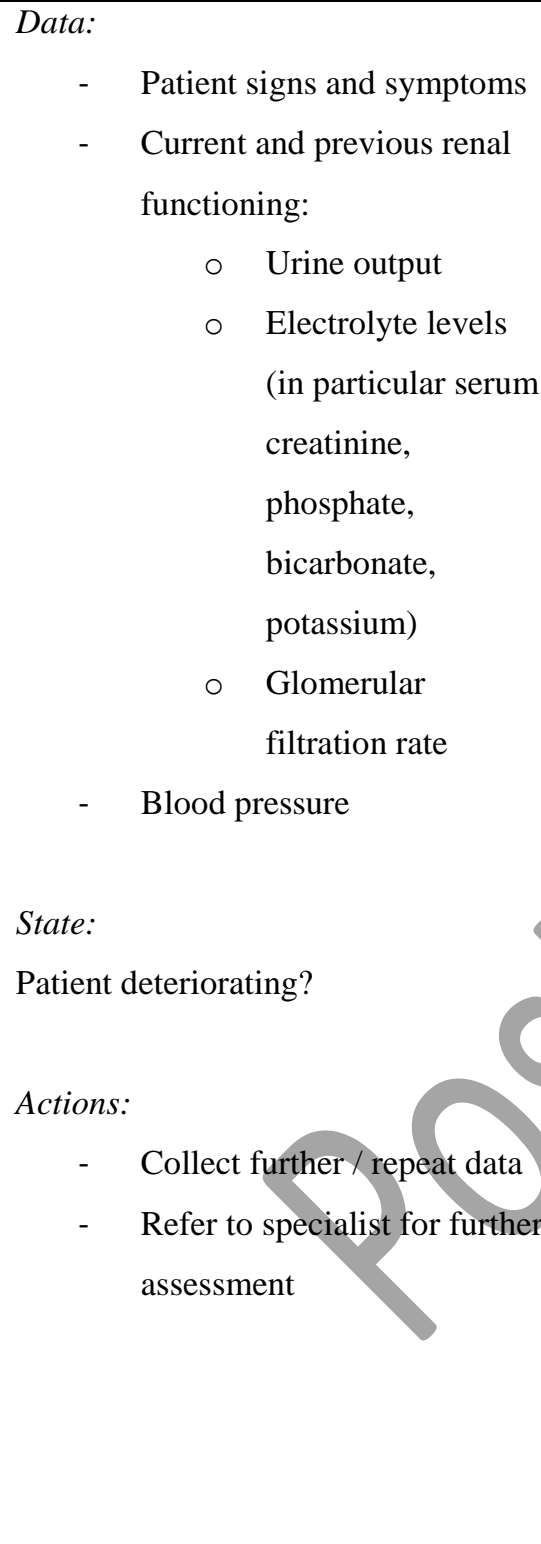 & 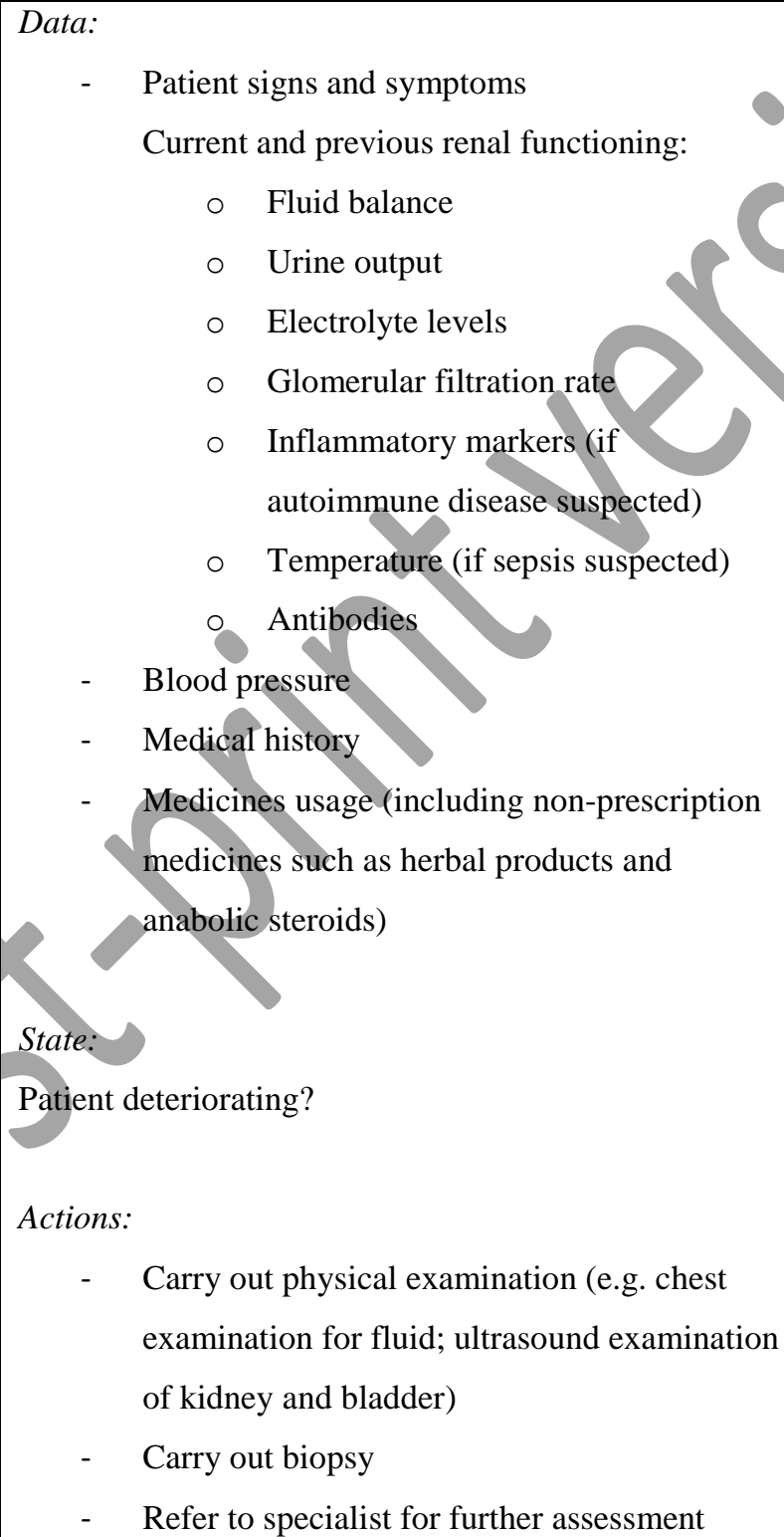 & Not applicable, as deterioration has been resolved \\
\hline
\end{tabular}




\begin{tabular}{|c|c|c|c|}
\hline \multirow[b]{2}{*}{ Function } & \multicolumn{3}{|c|}{ Scenario } \\
\hline & Initial onset (start of deterioration) & Advanced onset (deterioration has progressed) & Recovery (deterioration has been resolved) \\
\hline $\begin{array}{l}\text { Management } \\
\text { of } \\
\text { deterioration }\end{array}$ & $\begin{array}{l}\text { Not applicable, as deterioration has } \\
\text { progressed beyond initial onset }\end{array}$ & 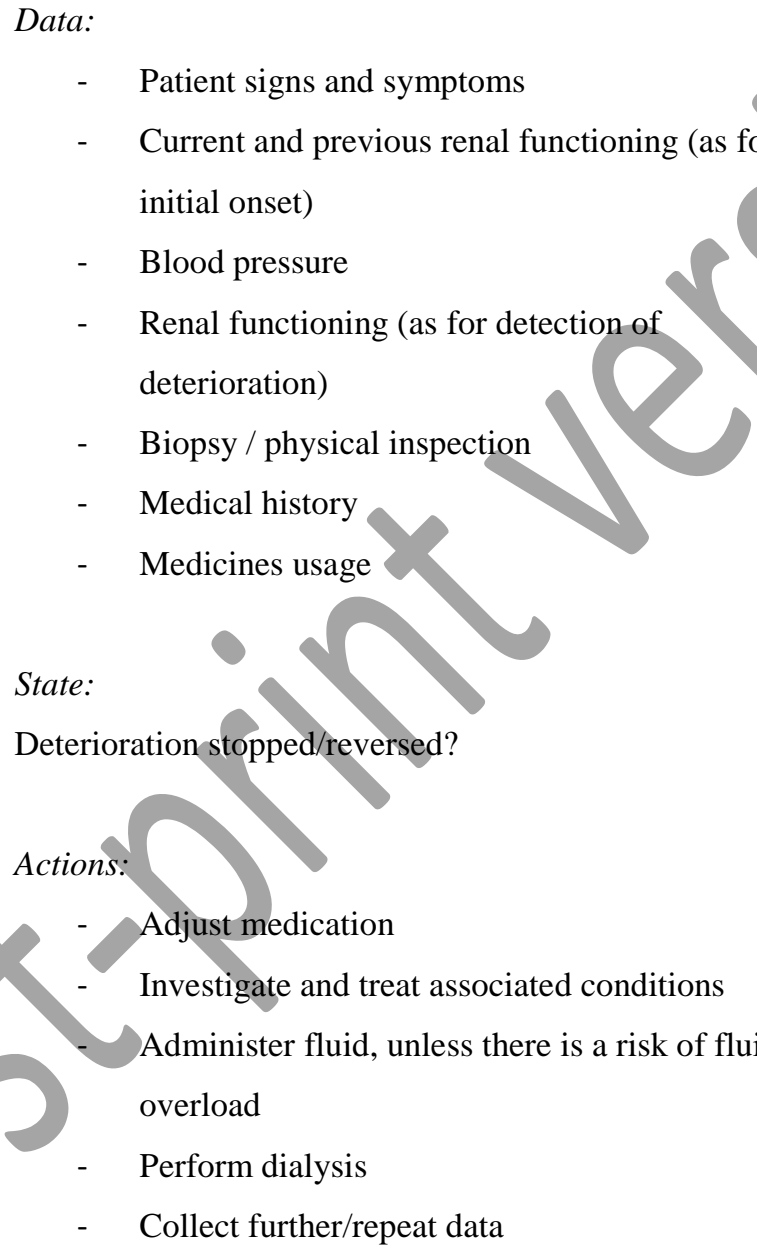 & Not applicable, as deterioration has been resolved \\
\hline
\end{tabular}




\begin{tabular}{|c|c|c|c|}
\hline \multirow[b]{2}{*}{ Function } & \multicolumn{3}{|c|}{ Scenario } \\
\hline & Initial onset (start of deterioration) & Advanced onset (deterioration has progressed) & Recovery (deterioration has been resolved) \\
\hline $\begin{array}{l}\text { Recovery } \\
\text { from } \\
\text { deterioration }\end{array}$ & Not applicable & Not applicable & $\begin{array}{l}\text { Data: } \\
\begin{aligned} & 0 \text { kidney filtration } \\
& 0 \text { creatinine clearance } \\
& 0 \text { urea and electrolytes } \\
& 0 \text { bicarbonates } \\
&-\quad \text { Blood pressure }\end{aligned} \\
\text { State: } \\
\text { Patient stable? } \\
\text { Actions: } \\
\text { - } \quad \text { Adjust medication } \\
\text { - Collect further / data }\end{array}$ \\
\hline $\begin{array}{l}\text { Note } \\
\text { "Adjust medi } \\
\text { drugs dependi } \\
\text { potassium lev }\end{array}$ & $\begin{array}{l}\text { on": adjust the dose of diuretics, ang } \\
\text { on the patient's condition. Angioten } \\
\text { Revise medication as appropriate fo }\end{array}$ & $\begin{array}{l}\text { sin-converting-enzyme inhibitors, angiotensin recept } \\
\text { onverting-enzyme inhibitors and non-steroidal anti-i } \\
\text { ng resolution of AKI. }\end{array}$ & $\begin{array}{l}\text { ockers, metformin and non-steroidal anti-inflammator } \\
\text { nmatories are usually stopped due to risk of elevated }\end{array}$ \\
\hline
\end{tabular}


Table 2(a). Decision requirements table for initial onset of AKI

\begin{tabular}{|c|c|c|c|c|}
\hline Goals & Cues & Expectancies & urse of action & System characteristics \\
\hline $\begin{array}{l}\text { Prevent } \\
\text { deterioration }\end{array}$ & $\begin{array}{l}\text { Renal deterioration indicated by: } \\
\text { - Reduced filtration } \\
\text { - Low creatinine clearance / high } \\
\text { level of serum creatinine } \\
\text { - Uraemia } \\
\text { - Low blood pressure } \\
\text { - Poor urine output / anuria } \\
\text { - Medication history in the } \\
\text { previous week includes: } \\
\circ \text { Diuretics } \\
\text { - ACE inhibitors/ARBs } \\
\text { - Metformin } \\
\text { Medical history includes renal } \\
\text { problems and/or sepsis } \\
\text { Received an iodised contrast }\end{array}$ & $\begin{array}{l}\text { Cues remain present across } \\
\text { repeat assessments } \\
\text { Improvement in renal } \\
\text { functioning after } \\
\text { medications affecting the } \\
\text { renal system are reduced or } \\
\text { stopped } \\
\text { Possible occurrence of: } \\
\text { - Dehydration } \\
\text { Sepsis }\end{array}$ & $\begin{array}{l}\text { If the patient is on a protein pump } \\
\text { inhibitor - consider whether } \\
\text { interstitial nephritis has occurred as a } \\
\text { result } \\
\text { Take on more fluid }\end{array}$ & $\begin{array}{l}\text { Patient physiology, } \\
\text { including the renal system: } \\
\text { - } \text { Functional purposes } \\
\text { - Abstract functions } \\
\text { - } \text { Generalised function } \\
\text { - } \text { Physical functions } \\
\text { - Physical form } \\
\text { Medicines management: } \\
\text { - Functional purposes } \\
\text { - Abstract functions } \\
\text { - } \text { Generalised function } \\
\text { - Physical functions } \\
\text { - Physical form }\end{array}$ \\
\hline
\end{tabular}




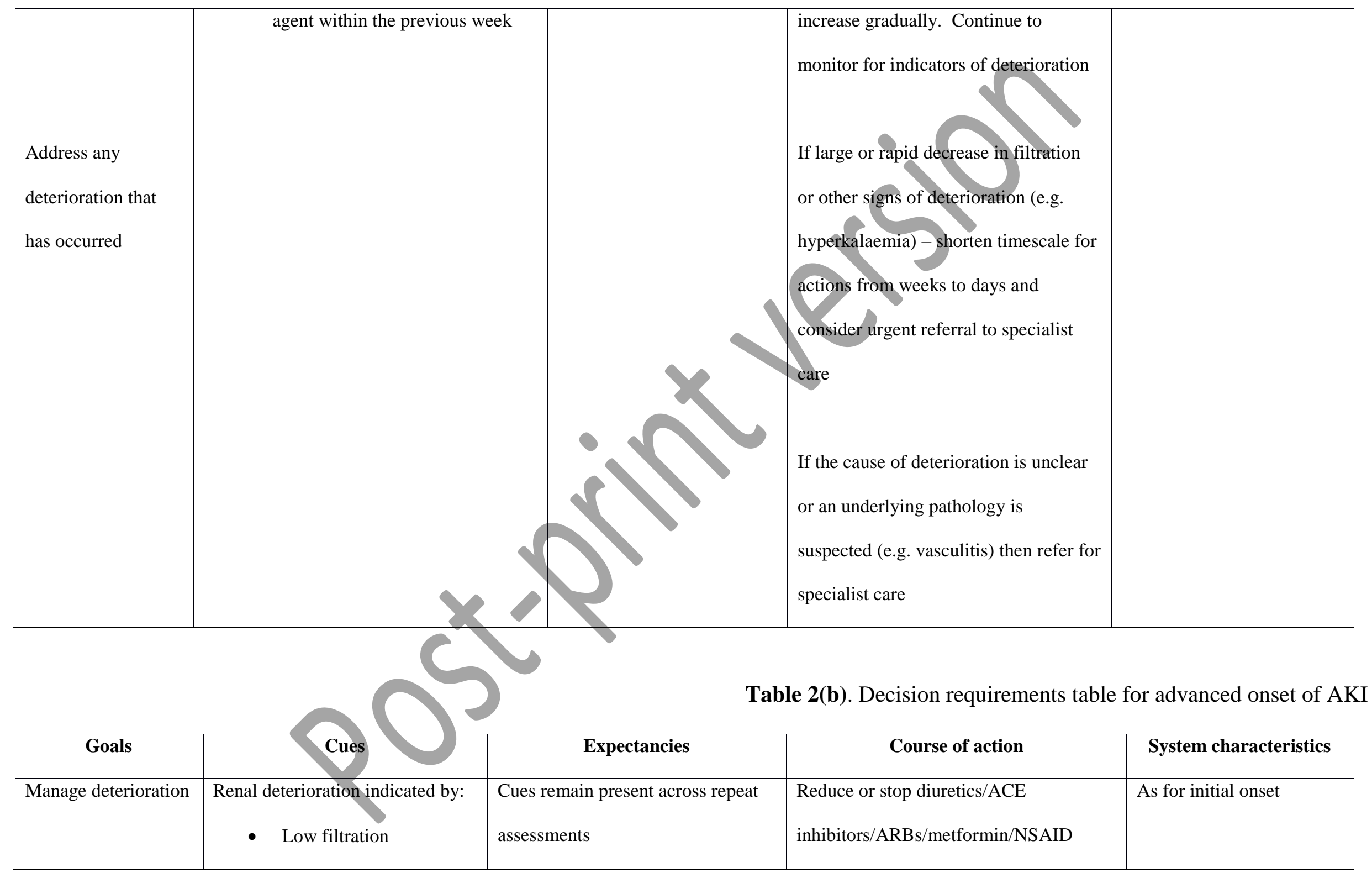




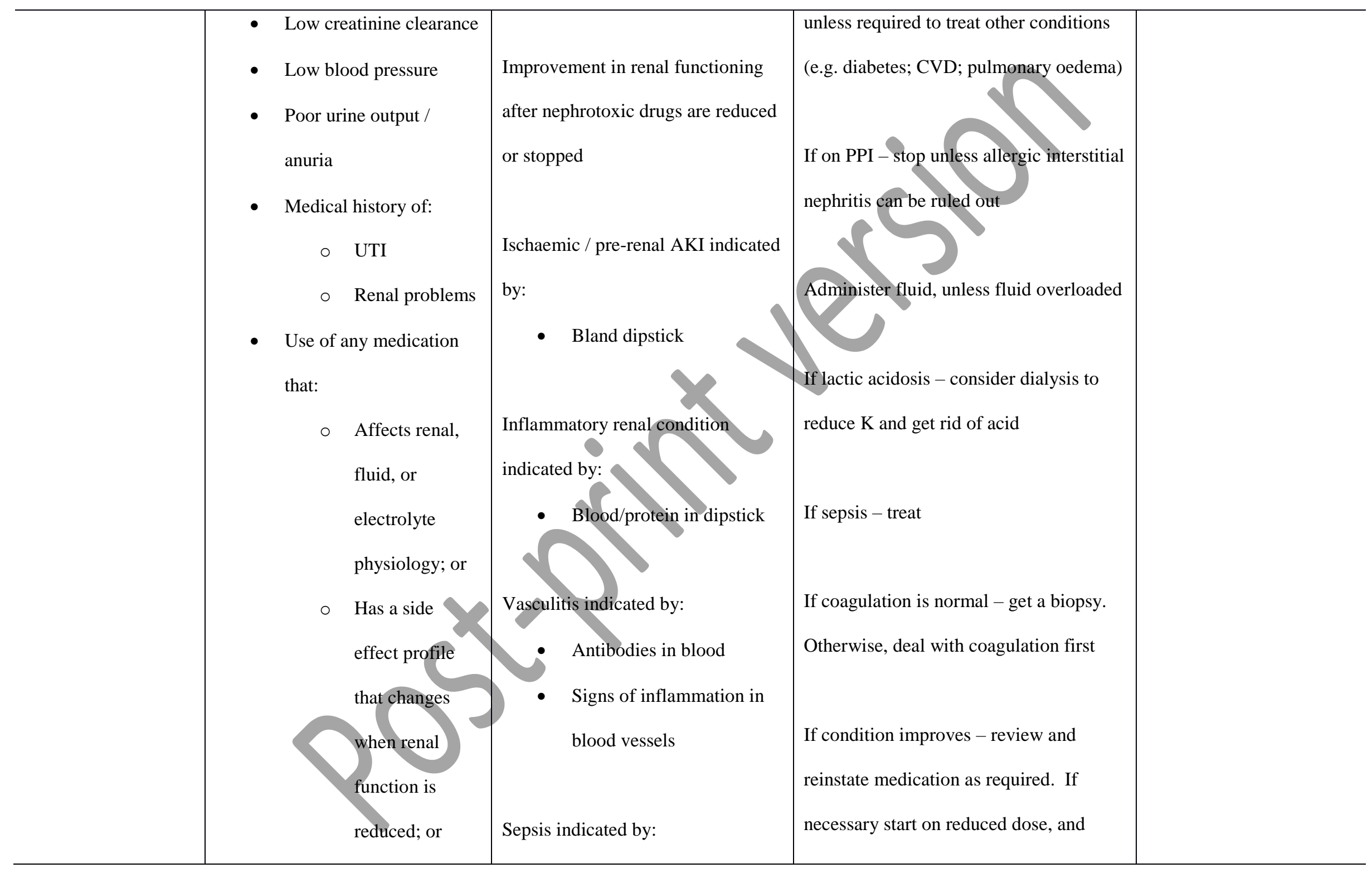




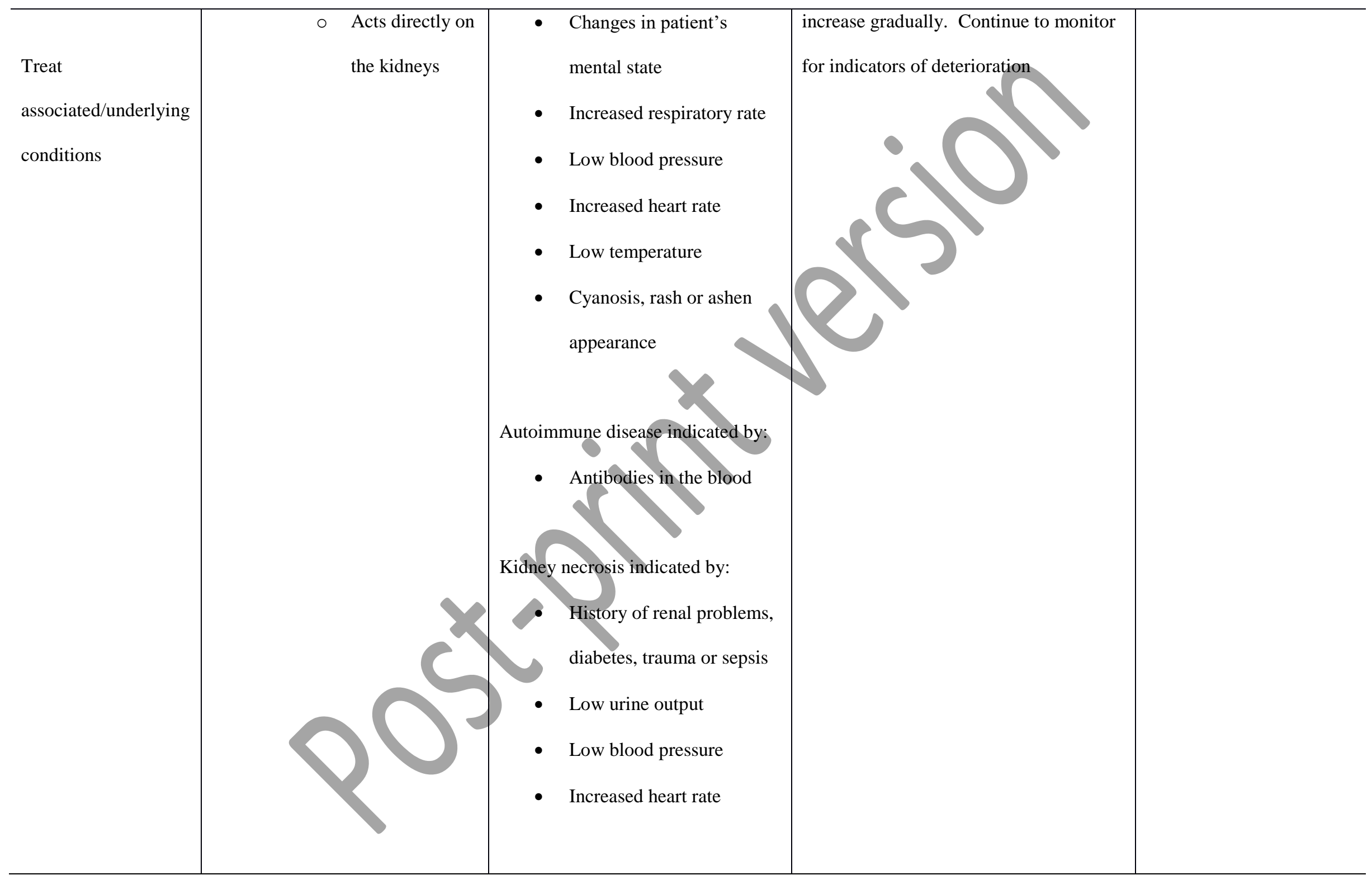




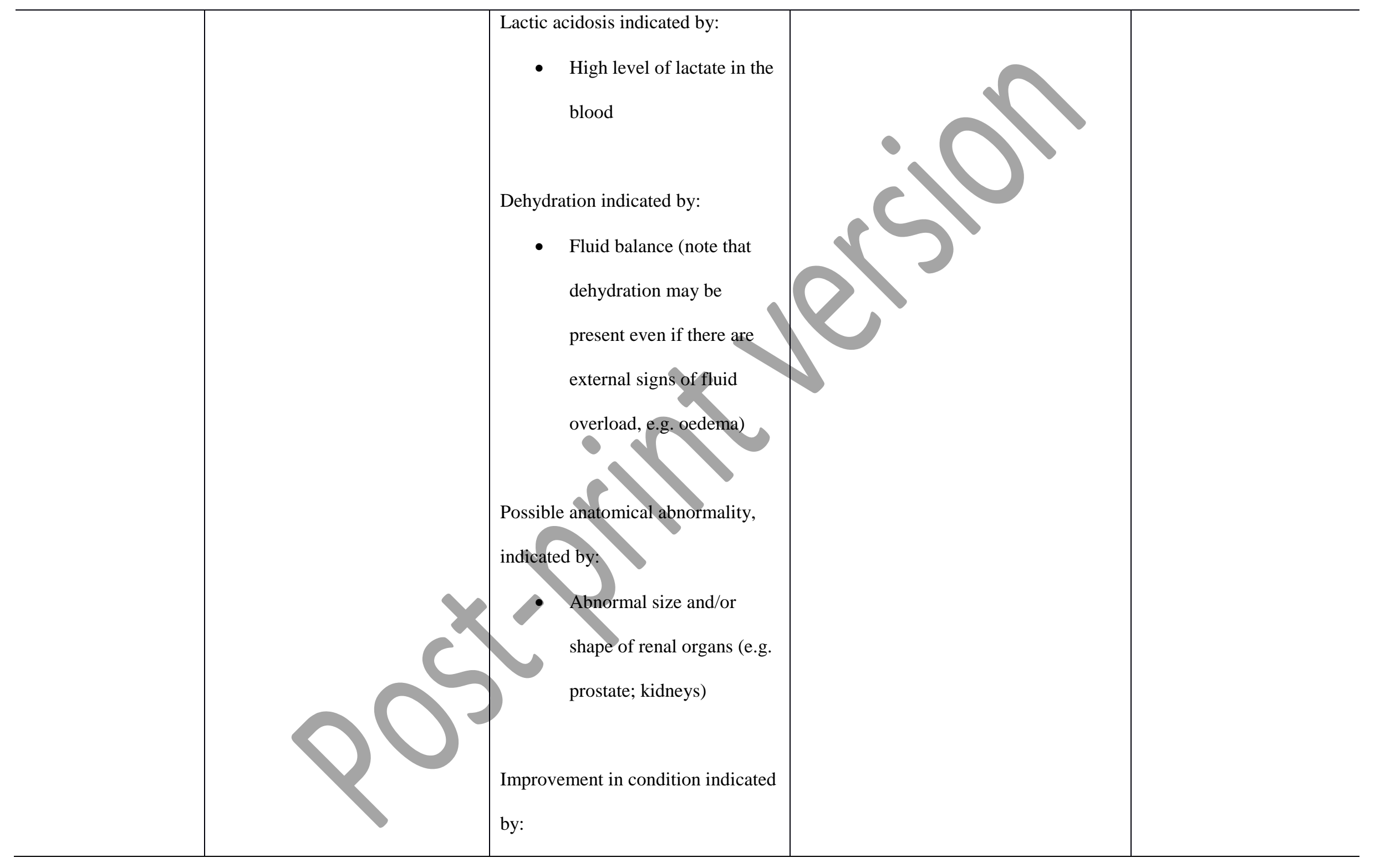




\begin{tabular}{|c|c|c|c|c|}
\hline & & $\begin{array}{ll}\text { - } & \text { Filtration } \\
\text { - } & \text { Creatinine clearance } \\
\text { - } & \text { Blood pressure } \\
\text { - } & \text { Urine output }\end{array}$ & & \\
\hline Goals & Cues & Expectancies & Course of action & System characteristics \\
\hline $\begin{array}{l}\text { Ensure maintenance of well- } \\
\text { being following prevention or } \\
\text { resolution of deterioration }\end{array}$ & $\begin{array}{l}\text { Recovery indicated by } \\
\text { improvement in: } \\
\text { - } \quad \text { Filtration } \\
\text { - Creatinine clearance } \\
\text { or creatinine level } \\
\text { Blood pressure }\end{array}$ & $\begin{array}{l}\text { Medication can be restarted or } \\
\text { adjusted as necessary. } \\
\text { However, this may cause } \\
\text { another episode of } \\
\text { deterioration in renal } \\
\text { functioning, or other adverse } \\
\text { effects } \\
\text { Risk of subsequent chronic } \\
\text { kidney disease, particularly if } \\
\text { the patient's renal functioning } \\
\text { does not return to its initial }\end{array}$ & $\begin{array}{l}\text { Review and reinstate medication as } \\
\text { required. If necessary start on } \\
\text { reduced dose, and gradually increase } \\
\text { to optimal dose. Continue to monitor } \\
\text { renal functioning and other relevant } \\
\text { indicators (e.g. blood pressure) until } \\
\text { satisfied that the patient remains } \\
\text { stable on the medication regimen. } \\
\text { Consider whether further follow-up } \\
\text { care is required (e.g. longer-term } \\
\text { monitoring of renal functioning) }\end{array}$ & As for initial onset \\
\hline
\end{tabular}




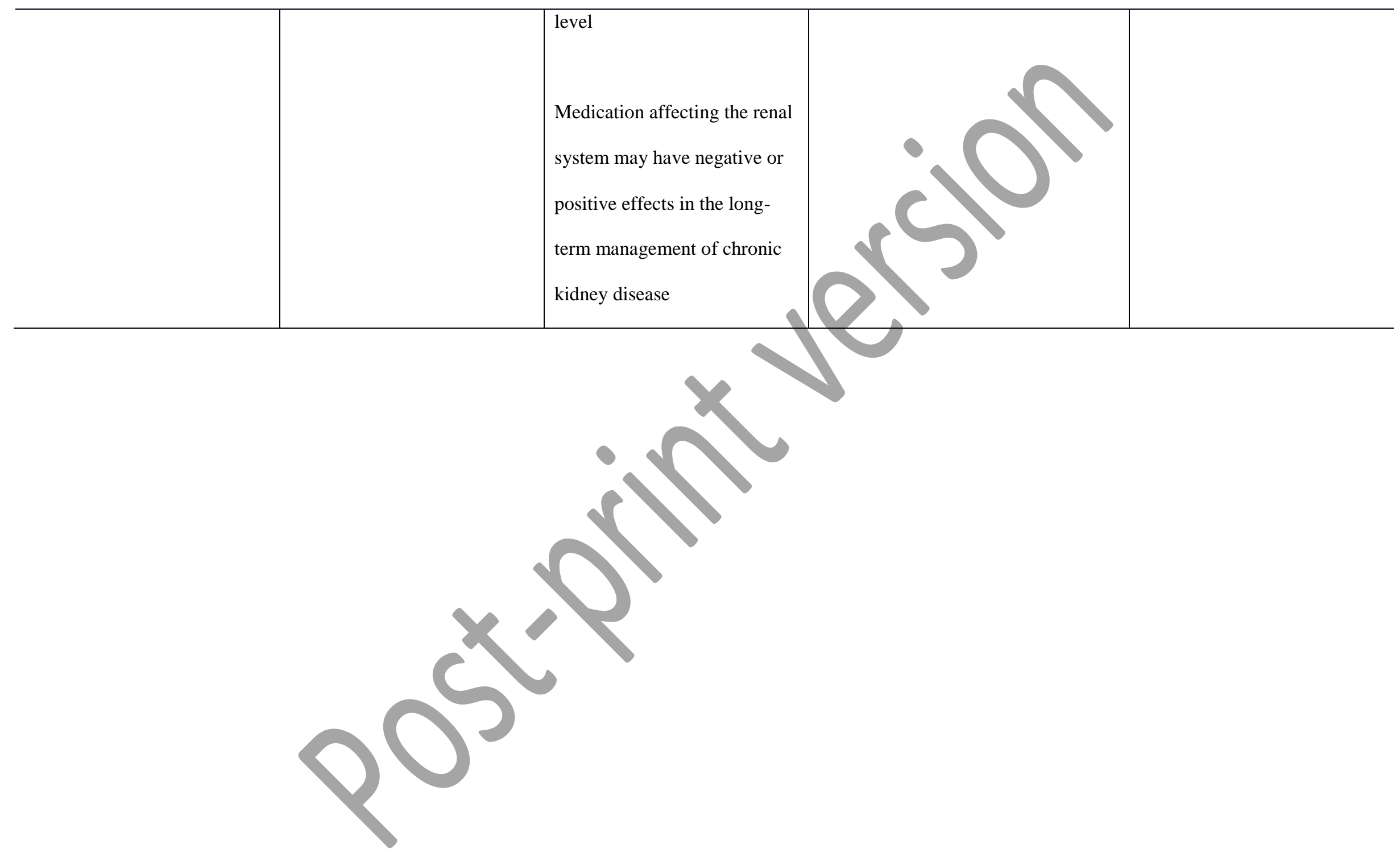


Figure 1. The abstraction-decomposition space for patient physiology in acute kidney injury

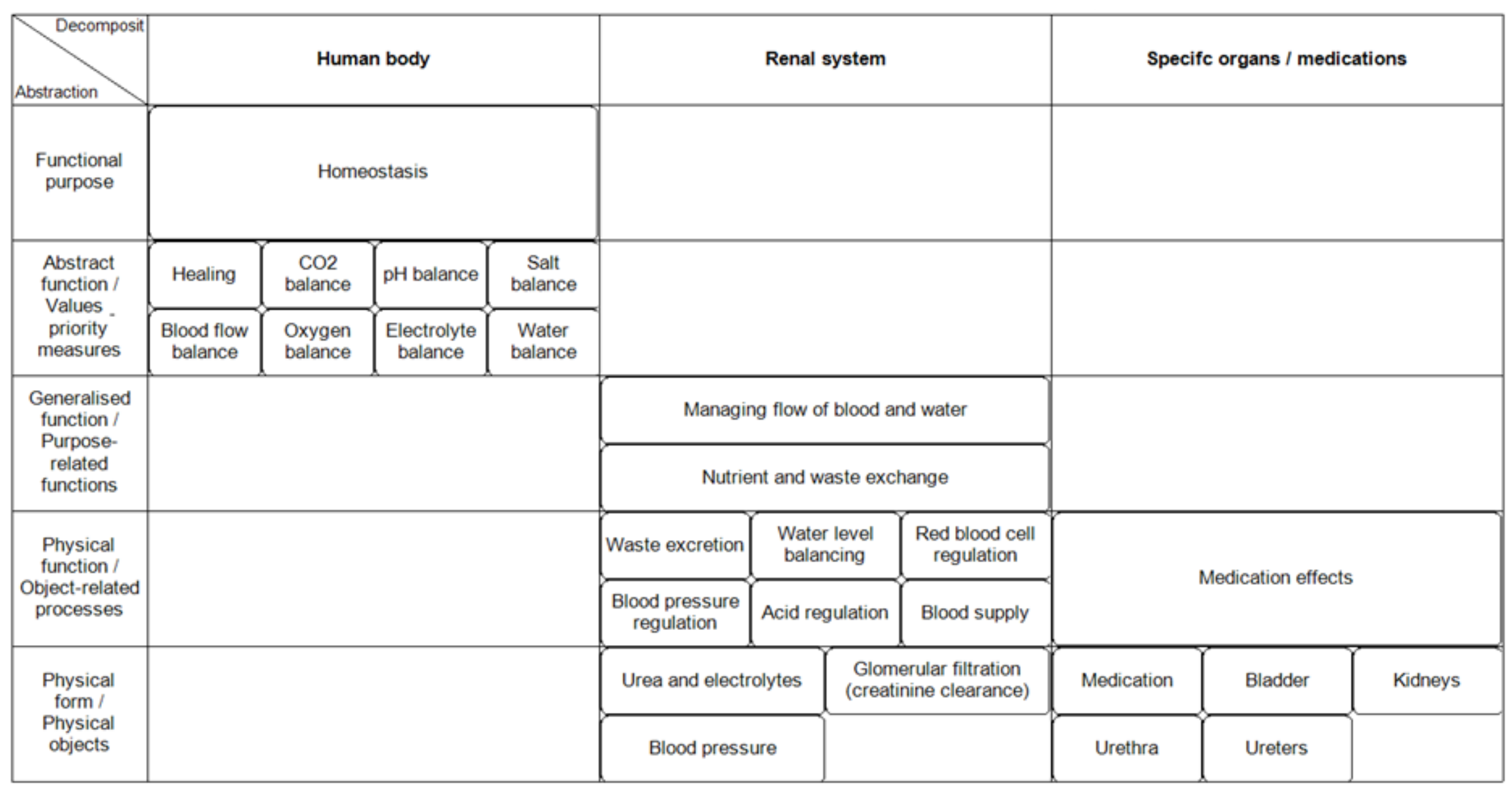


Figure 2. The abstraction hierarchy for medicines management in acute kidney injury

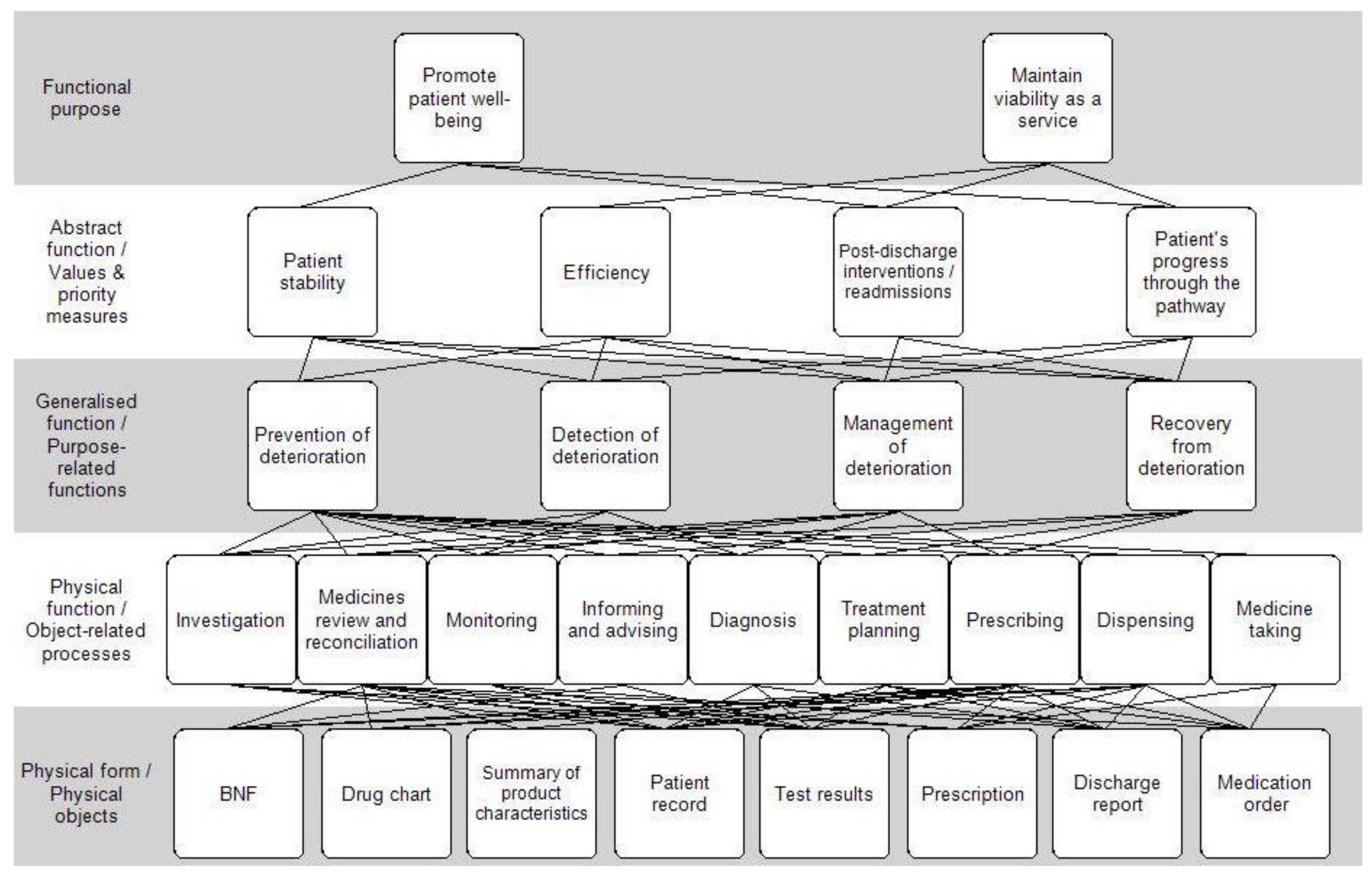


Figure 3(a). Information flow diagram for initial onset and recovery

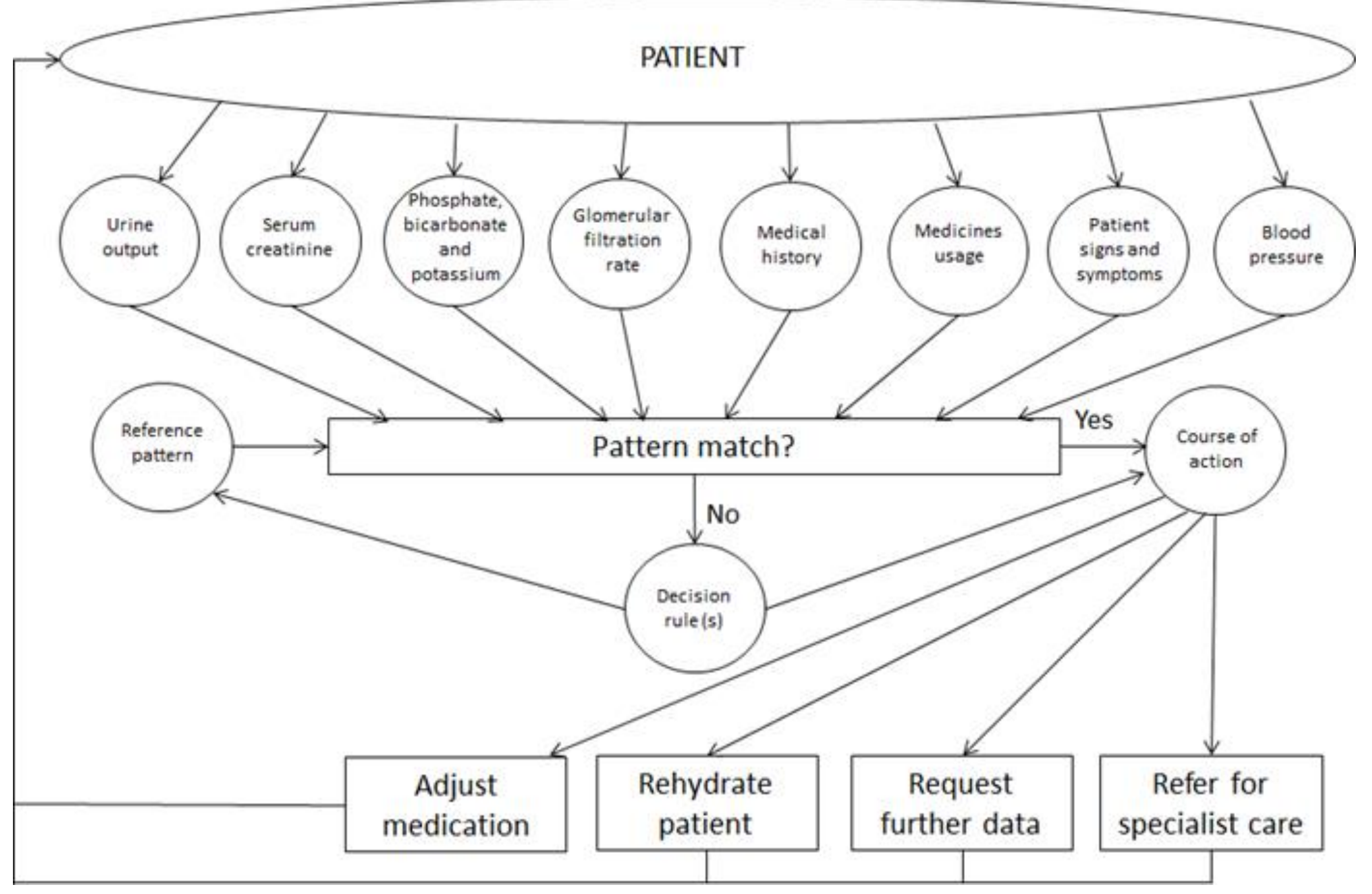


Figure 3(b). Information flow diagram for advanced onset

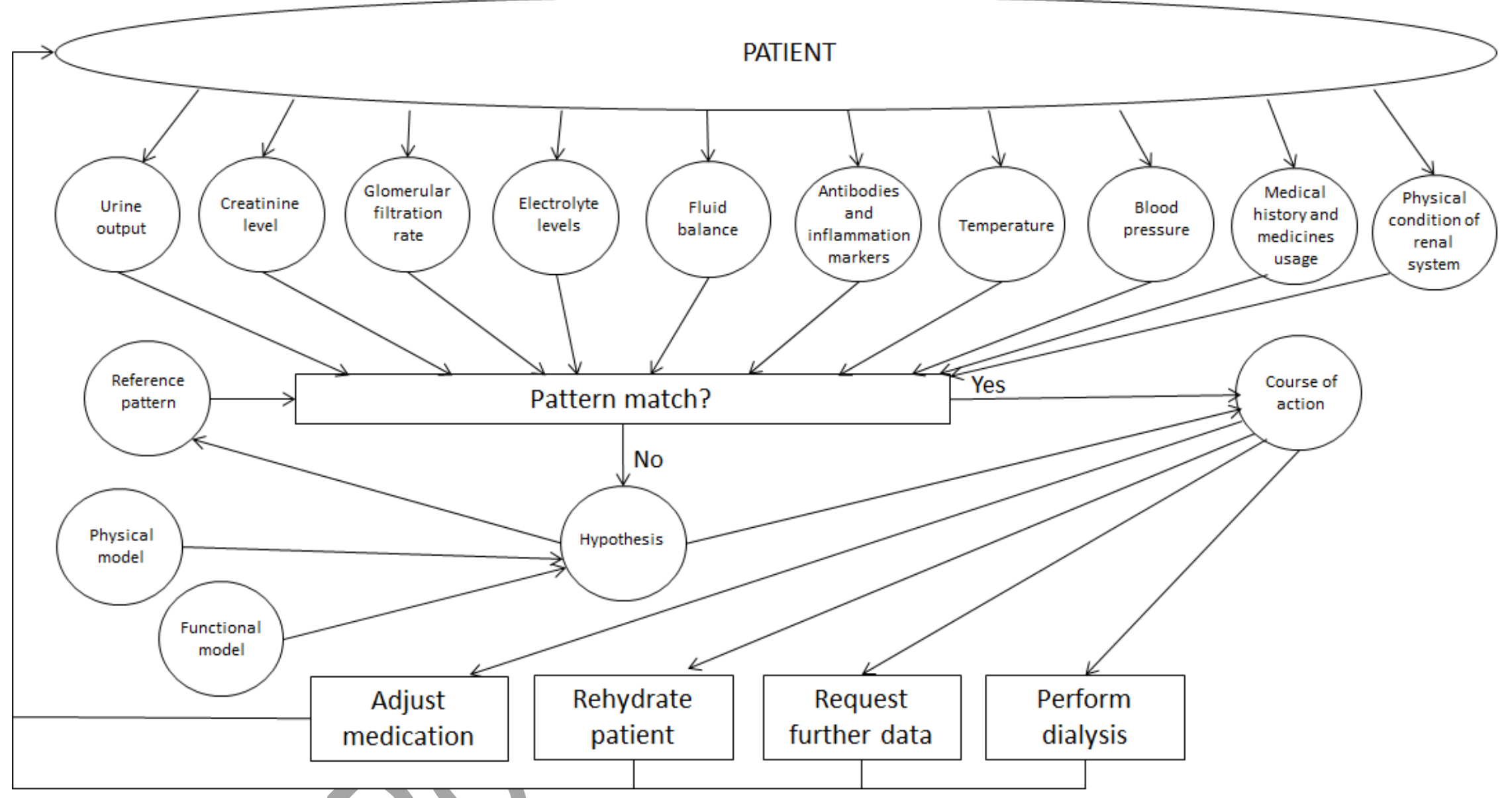


Appendix 1. Interview schedule for collection of primary data

1. What is your experience of working with AKI patients?

2. Tell us about the setting in which you work (probes in italics):

- What are the objectives of your work?

- How do you know whether those objectives are being met?

- What needs to be done in order to meet the objectives?

- How is the work done?

- Who and what is involved?

3. I'd now like to talk about the transfer of patients between primary care and secondary care during an AKI episode (probes in italics):

- What is the process for doing this?

- What problems do you encounter, and how do you overcome them?

- Describe a situation in which you had to deal with a patient with AKI. What was happening?

What were you expecting to happen? What were your options? What did you do? Why?

What was the outcome? 
Appendix 2. Definitions used to populate the abstraction hierarchy from the interview data (adapted from Naikar et al., 2005)

\section{Functional purposes}

Why the system exists; what role it plays; what restrictions of demands the environment places on the work system. For example: objectives; aims; reasons; laws; regulations; constraints.

\section{Abstract functions}

How we judge whether the work system is achieving its purposes; what the system priorities are; how we decide how to allocate resources. For example: criteria; targets; policies; principles.

\section{Generalised functions}

What functions are required to achieve the purposes of the system; what individual and teams do within the system. For example: roles; tasks; duties; activities; operations.

\section{Functional processes}

What physical objects in the system can do; what they are used for; what things need to be done in order to carry out the functions. For example: applications; characteristics; utilities.

\section{Objects}

What the physical objects and processes in the system are; what their characteristics are; how they are organised. For example: equipment; devices; staff; buildings; supplies. 